\title{
Psychic itinerary of the cesarean section in six Cameroonian primiparous
}

\section{Mireille Ndje Ndje}

$\mathrm{Ph} / \mathrm{D}$ in Clinical and Pathological Psychology, Laboratory of Development and bad Development, Faculty of Arts, Letters and Human Sciences, University of Yaounde I, Cameroon

\begin{tabular}{|c|c|}
\hline ABSTR & \\
\hline $\begin{array}{l}\text { Statement of the Problem: The birth of a child does not create } \\
\text { a split with the pregnancy and desires of the conception of the } \\
\text { parents but rather confirms the continuity of the fantasies, the } \\
\text { representations which animate these and more still the mother } \\
\text { since the desire of the child. These fantasies and daydreams in- } \\
\text { herent in pregnancy and described by Bydlowsky are relegated } \\
\text { to the background, and sometimes even ignored by families, but } \\
\text { especially by obstetric care professionals during birth. Method- } \\
\text { ology: This article is an intrusion using semi-directive interviews } \\
\text { in the psychic dynamics of six Cameroonian primiparous women } \\
\text { who gave birth by cesarean section in a specialized hospital, } \\
\text { from the preoperative to the postoperative through the opera- } \\
\text { tive. Findings: It emerges from this study that when the normal } \\
\text { process of birth is changed, the mother can undergo this event } \\
\text { considered natural in her cultural universe. Cesarean section is } \\
\text { certainly a birth, but it is anti-physiological, because of the lack } \\
\text { of passage that leads to a feeling of foreignness in women. In } \\
\text { the Caesarean section, there seems to be a lack of narcissistic } \\
\text { investment in the reproductive apparatus. Caesarized parturi- } \\
\text { ents feel guilty for not having given life according to the accepted } \\
\text { model, both on the religious, social, cultural and psychic level. } \\
\text { They feel guilty for not being able to repeat the act that wom- } \\
\text { en have been doing in their environment since the beginning of } \\
\text { time. For their own family they bring denigration, for the in-laws } \\
\text { they are incapable, for the other parturients they are inferior, and } \\
\text { for themselves they are guilty. Conclusion: This birth-related } \\
\text { surgery does not give women a leeway to become involved in } \\
\text { the process. The physical undergoes invasive gestures that are } \\
\text { not felt in a present but are imagined with a shift of time, of real- } \\
\text { ity and resonance on the psyche.Key words: Psychic itinerary; } \\
\text { cesarean section; maternity; operation; guilty. } \\
\text { Keywords: Psychic itinerary; cesarean section; maternity; oper- } \\
\text { ation; quilty. }\end{array}$ & $\begin{array}{l}\text { *Correspondence to Author: } \\
\text { Mireille Ndje Ndje } \\
\text { Ph/D in Clinical and Pathological } \\
\text { Psychology, Laboratory of Devel- } \\
\text { opment and bad Development, } \\
\text { Faculty of Arts, Letters and Human } \\
\text { Sciences, University of Yaounde I, } \\
\text { Cameroon } \\
\text { How to cite this article: } \\
\text { Mireille Ndje Ndje.Psychic itinerary } \\
\text { of the cesarean section in six Cam- } \\
\text { eroonian primiparous. International } \\
\text { Journal of Psychological Research } \\
\text { and Reviews, 2019, 2:11 } \\
\text { eSciPub LLC, Houston, TX USA. } \\
\text { Website: http://escipub.com/ } \\
\text { Q ÎP Ub }\end{array}$ \\
\hline
\end{tabular}




\section{Introduction}

Caesarean section is an increasingly common surgical procedure. It is usually done when natural delivery is not possible or is too risky for the mother or baby or both. It can be decided in advance during the consultation with the gynecologist who has planned the impossibility of giving birth vaginally. It can also be decided urgently, during work when a complication occurs. The biomedical device can reassure women about the good biological course of pregnancy, but it evacuates all the psychological experience related to it, in terms of belief such as childbirth is inherent to the woman, it is a natural affair and obvious. Women know that in many cases, if the body is allowed to do its job, children are born. The delivery must be done in pain that is rewarding for the woman. Medicalization is delegitimize and ignores women's expectations of childbirth, an experience that transforms their bodies, their lives and their sense of life. By not insisting on the importance of taking into account maternity as a whole, taking into account the expectations of women themselves, of the family and of society as a whole, the psychological experience of motherhood, cultural and religious rules related to motherhood to linger only new sophisticated techniques that surround it, we risk the evacuation of women from significant fields.

The medical profession is competent, but it risks placing the parturient in a state of incompetence. We can not absolutely identify women who are predisposed to cesarean section, which will diversify their reactions. However, one can take a look at the impact of the surgery. According to Bradley et al. (1983), caesarean section would be an easy experience to assimilate. Three facts are usually linked to the quality of the caesarean section: whether it is elective or urgent, whether the anesthesia is general or loco regional, and whether the parturient has benefited from a preparation or not. On the other hand for Mercer et al. (1983), the experience of cesarean section would be more negative than that of a vaginal delivery.

\section{Cesarean and vaginal: fresh perspective}

Surgeons occupy a prominent place in the event that is giving birth, "theydeliver" Jones (1976) to mean they give birth. However, vaginal delivery is an opportunity for women to feel, to live, to confront, to experience, to integrate and transcend pain, not only in their bodies, but also in their lives, with the meaning that they give it, such as childbirth is an opportunity to learn over oneself and over life. For Amselek (1998), delivery contains in a condensed form, as one could say, all the maternity which is put into action, and which is dramatized throughout the body. Through the absence of sensation of pain the parturient does not only lose contact with pain but also with a part of oneself (Rich, 1976). The pain reminds us again and again to go back to our positions, to investigate more deeply, to let the present moment be what it is and to observe what is going on in the fullness of the next moment, Levine in (Brabant, 1987: 14). The anesthesia experienced by cesarized parturients deprives them of the pain of childbirth, which is nevertheless rewarding. Indeed, the pain of childbirth differs from other pain that a person may experience in his life, which are signs of discomfort or even a malaise, an injury, the beginning of a pathology, a disease. The pain is integrated into the gestalt of the birth and is part of the normality of this process. It signals the child's coming, which makes it positive. "Childbirth bread is normal, healthy bread" (Cohen, 1983: 267). It calls for an awareness of the process that is beginning and the precise expectations of women in each culture. Caesarean section modifies these functions hitherto assumed by the female body. In Africa, maternity finds its definition not only in the vagaries of the particular mental structure of the parturient and in the fertilization which triggers from the fertilized egg in its body the pregnancy which will lead to the birth, but also in the expectations, codes and rules defined by her culture. By giving birth to a child, the woman is transformed and becomes a mother in addition to being a woman. This passage gives birth to 
the mother in joy as in anger, in pain as in suffering, that she arrives there alone or that she is operated, with an important baggage. When she is going to be alone with herself, this memory will cause reworking. Childbirth allows women to take a step in their lives, to evolve, to recognize themselves, to feel stronger and more competent. It is also an opportunity for them to feel connected to their own mothers, other women who have had children, their families and even other women around the world. The weight of pregnancy, the pain of childbirth, the constraint of breastfeeding, are deeply feminine gifts that give access to things that men do not access.

\section{Methodology}

Through six semi-structured interviews, we exchanged with six first-time mothers about the experience of cesarean section during the period from conception to operation. From these interviews, it appears that the psychic itinerary of cesarean section in primiparous women that we have followed takes place in three main phases. In antepartum, perpartum and postpartum. The age of our participants varies between 19 and 30 years. The age criterion was very important, we avoided the parturients who despair of having a child because of the advanced age.

\section{Findings}

\section{Pre-operative experience}

It is the period before the surgery

\section{Psychosocial experience}

This one introduces to the interpersonal relations of the woman, in particular conjugal ones. The most common aspects are those with the spouse, family and therapy.

\section{Spousal relations}

Most subjects have good relationships with their spouse. If they are not idyllic, the spouse assists them during their pregnancy, bringing them affection, material and psychological assistance. Some of the ladies are talking about it. In the case of Mrs. D, we note the following: "I married two years ago and my husband does not hide that he loves children, he repeats it to me every day. When he knew I was pregnant, he really changed. Also, becoming pregnant brings benefits to the woman. She becomes like the good object and attracts the attention and favors of her husband. Despite this, she continues to be very active". "And I had a lot of strength, I did not stop my activities until the last minute". It must be remembered here that Mrs. $D$ is a shopkeeper and that she must be daily at her establishment.

Mrs. E also presents similar information "My husband too, he was eager to be a dad. When I told him my periods did not come, he shouted for joy. He immediately began to select the first names, he was very happy". There is in this contentment of the husband the expression of the desire and the need of a child who can only influence the lady. In spite of an anxietyprovoking influence, there is the possibility of existence of fears and fears of failure. Everything happens as if the spouses have perspectives that give them a great pleasure and already that of being "dad", but that the lady to feel oneself, have to integrate these goals while realizing themselves.

\section{The relation to the mother}

The relation to the mother participates in the psychosocial experience in a complex way. The mother indicates what to do during pregnancy. In this respect, she plays a role in the perpetuation of traditions, psychosocial and therapeutic care. Mrs. A insists: "I respected the prohibitions that my mother told me and since it was my first pregnancy, I followed all the advice. I even followed a special diet. At home we say that the first baby must succeed for others to follow his example. That's why I took all these precautions".

Here reference is made to beliefs and representations related to traditions. There are standards to respect, customs to protect, otherwise the pregnancy and the child may suffer. Everything indicates the need for the subject to be in accordance with family and cultural norms. Mrs B does not speak directly of her mother preferring, without a doubt, to restore 
her in the continuity of the tradition. "In the neighborhood, women tell a lot about pregnancy, they say that we must drink some drugs, purge myself. I did not do anything about it. I followed the advice of my doctor. It is true that when I lost the mucous plug, I purged myself because I was afraid to do the stool on the delivery table. I blew myself only three times. This child, I so desired him". Mrs B reports the consequence of these cognitive influences on her behavior. This made her anxious because she was afraid of "making the stool on the table". There is a risk of self-harm that emerges here. Mrs. D speaks as follows: "My mother had even come to stay with me, my sisters passed regularly. Even my sisters in law were present". Mrs. E insists on the relationship to her mother. It is full of protection and protective feelings of the mother vis-à-vis her daughter: "During my pregnancy, I know that I ate well, there is nothing to say. I only ate foods that give strength. Hey! I avoided things that are often forbidden, be it food, meetings, going to strange places. My mother gave me some special meals that help the pregnant woman." Here we can see, through the relationship with the mother, ethnopsychiatric and ethnopsychological factors. We thus note the presence of prohibitions related to customs. Hence the existence of ethnocultural factors in relation to childbirth with their psycho-cognitive implications. Fear and anxiety are reflected in the words "weird places". For this is how Mrs E qualifies the places of frequentation for their foreignity. In African culture the odd places for the pregnant woman are potentially bearers of misfortune. These are, for example, funeral ceremonies, especially those where one accompanies the corpse of a person with antisocial behavior decried by many. Similarly, the notion of special meals refers us here to meals that have a positive impact on the wellbeing of the child and the mother, both biologically and psychologically. Ms. F's case highlights the cognitive relationship with the mother, here the aunt. What is described is the pedagogy used by it "I did not feel anything, as women often say that they are tired, no I had no problem. This is my first time so I did not know what can happen. My aunt had explained to me a little, she had told me that it was easy but I had no idea. I often hear moms talk about pregnancy and childbirth. Women give birth alone, without going to the hospital. There are also moms who help young people like us." Here we observe the influence of the mother who is an educator. She teaches her daughter about motherhood and pregnancy. She prepares her for childbirth by telling her that this is a dramatic step in life, but one that can take place when you know how to do it. In the case of Mrs. F, there is also a tendency to follow the tradition and rely on it "If it was only me, I was going to give birth in the village. There they take good care of you. Here I ate everything while in the village there are special foods for pregnancy ". In one case, it must be pointed out that the relation to the mother appears conflictual. Ms. C explains that "I do not believe in witchcraft, which is why I refuse to believe that something has been done to me. Even the stories of a pregnant woman does not do that or that my mother told me, it does not interest me". There is opposition and conflictualization at the level of psychocultural clan capture and how they should govern the lives of the subjects. Mrs $C$ shows that while feeling African and of Protestant denomination, an ambivalent relationship exists with regard to the system of care and traditional psychosocial assistance.

\section{The pregnancy}

\section{How is the announcement}

In Ms. A's case, the doctor's information is contradictory, and the announcement of the operation is unprepared. The doctor simply highlights the cause-and-effect relationship. "The doctor even said that my cervix was well dilated. Everything was going fine. Suddenly, the same Doctor came to announce me some time after that my child has the cord around the neck and that he begins suffering. He then said that I must operate". Ms. B is abandoned by her 
doctor, who has noticed that she has a problem. She is referred but unfortunately for her the new doctor does not bring any insurance and announces a more serious news, that of the operation "The third day I left to the hospital and this is where my doctor told me that the baby was misplaced and that he had to travel. So he advised me to come here. I arrived here on November 2nd, I did not even have contractions, but I was kept in the hospital. The doctor here prescribed an ultrasound that confirmed that the baby was misplaced. He told me that they will operate on me." The doctors who take care of her later on are no more reassuring and rather make the news difficult. "That famous day, during the morning round, the one who presented my case said that I told him that I did not want to be operated on. A doctor, it must be one of their chief said, "it's ok we will operate it". For Ms. C, the news was heard long before, so she had time to integrate "It is towards the eighth month that he told me the child did not always returned. He said that we observe and if it remains so until the end we will operate."

The announcement at Mrs. D is marked by the ambivalence of the doctor. He is not sure of his diagnosis, but chooses to refer the lady. She decides to go to the hospital of her choice but there they are no longer worried and fear the worst "At the end of my pregnancy, the doctor who was following me at the clinic told me that he was no longer sure that everything was fine and that I could be operated. He told me to go to the central hospital. I did not want to go there, so I came here. When I arrived, I was prescribed an ultrasound. The doctor I met here said that the baby had the cord around his neck. He therefore confirmed the concerns of the other doctor. He told me that I will be operated because if we try to get the baby out normally, he can die." Ms. E's doctor also has suspicions that will be confirmed by ultrasound. The doctor presents the operation as essential but leaves her the choice of the date which is already itself conditioned by contractions "So when I came for an Nth visit, I think it was 38 weeks, the doctor told me that the baby is very big and prescribed me another ultrasound. I did the ultrasound the same day. The next day when I came to present the results, he told me that the baby has $3700 \mathrm{~g}$ and that my pelvis can not pass it. So he said he absolutely has to operate on me. He also told me that I can choose: either I get surgery here like that, or I expect to have contractions ". Mrs. F has the impression that we wanted to hide something from her. The operation is advertised as information that has been processed outside of her "When my husband came, they went out to talk. I was already in pain. The doctor came back and he said that the baby is suffering, that I have to be operated."

We can note in the announcement of the operation ambivalence among doctors who will use either ultrasound as is the case for Ms. E, or they will refer their patient Ms. D, Ms. B. The ad in all cases without preparation, even when there were suspicions in advance, which could justify the reactions of the participants.

\section{Conflicting feelings at the announcement}

The majority of reactions among these participants are emotional reactions that become somatic. At Mrs A's, we can note the shock "When I was told that I was going to be operated on, I started to cry and the Doctor told $m e$ "it's going to be okay ", then I'm told leads to the block. Mrs. B is also shocked and says it clearly "I cooled, I felt as if my heart stopped. I told the doctor that I was not ready for an operation ... It shocked me." Ms. C did not have time to react right now. The events went very quickly "As soon as I arrived, I was led directly to the block. I was undressed and put on a table. Moments later, I was injected and fell asleep." Mrs. D shows that she was disturbed and also somatized "I felt my heart stop. My fingers were wet, I do not even know if I was breathing."

Mrs. $E$ is shaken by the news and notes somatic reactions "I have felt the blood freeze in my veins". The shock is clearly expressed in the case of this lady "I told you that when I was told that we will be operated, it traumatized me, but it was nothing. When I was stung on the back 
before the operation, I felt as if the electricity hits me."

Ms. $F$ is rather paralyzed. The news even inhibited the pain she felt "I swear to you that even the pain I felt before went away". We can note in these ladies, apart from Mrs. $C$ who does not speak of her reaction, that there was shock at the announcement of the operation. This shock

\section{Strategies adopted}

Mrs. A projects the blame on others and abandons herself to her destiny "Ah maybe it was God who also wanted, maybe he does not want me to have many children. Oh maybe it's my fate." Ms. B is upset by the news but chooses to calm down "I wondered how I was going to announce this to my fiance. How can I start my first childbirth with an operation? I stayed calm." Ms. C also abandoned herself to medicine feeling helpless. In Mrs. D's case, we see the fear of facing reality against her husband. The lady chooses to confide in her little sister "I told my little sister everything. I did not know what to say to my husband." Mrs. E let herself go, she resigned herself and abandoned herself to medicine. Mrs. F did not hold and collapsed "I only turned my face and started crying. I was so discouraged. "Three of these ladies, Mrs. B, Mrs. $\mathrm{C}$ and Mrs. $\mathrm{E}$ made the choice of resignation. One, Mrs. A chooses to get rid of the blame and throws it on others while Ms. F collapses. Ms. D is going to get support from her little sister.

\section{The intra-operative experience}

This experience is complex because of the relationship between each woman and her mode of operation. The six participants are not operated for the same problem. Two of them have a cord circular as indication of caesarean section, one is in the case of foeto-pelvic disproportion, two have a problem of fetal position, and one has a problem of fetal distress. Because of not having the same problem initially, these women did not adopt the same strategies. On the other hand, five had general anesthesia. Anesthesia is the practice of nerve inhibition of the organs of the body and when it is important, leads to a total asleep of the one who undergoes it, by reduction of the vigilance. Many people avoid anesthesia, because they have the impression that in case of medical error, they will not wake up. Generally, it is the surgeon who decides what kind of anesthesia to apply. He may feel that the patient will be very distressed by what he will discover as the live injury, the flow of blood etc. Psychologically, anesthesia is as follows in our participants: For Ms. C, it is an object of sidelining, as a capacity inhibitor. The lady says, "I was undressed and put on a table. Moments later, I was injected and fell asleep. I woke up the next night and here I am." Mrs. D shows her fear and anxiety about anesthesia. This anxiety is going to be somatized and the lady will resign herself "We bought the equipment and I entered the block. There it was as if they put me in the freezer, I felt my fingers stiffen and I did my prayer. I gave everything to God and I stayed calm. They injected me and I do not know what happened."

Mrs. E talks about the pain of anesthesia, and the shock it can cause "When I was stung in the back before the operation, I felt as if the electricity hit me. It hurts a lot and it's really traumatic. The rest, I do not know. I only saw the baby."

Ms. $F$ feels that she is in danger as soon as she enters the operating room. The language that is spoken seems to her to be chosen on purpose so that she does not know what is going on against her. The injection she receives confirms her fears since she has further removed from the scene of her delivery "I was brought to the block. There, everyone was speaking only English, so I do not even know what they were talking about. I was stung and fell asleep until yesterday or I found myself in this room with a baby next to me. "

One of the participants experienced local anesthesia. This anesthesia consists of the inhibition of the sensitivity of the zone that will be mobilized during the operation. In principle here, the patient is awake and can attend the 
operation, at least the part that we want to make visible. Mrs. B who has experienced this type of anesthesia presents it as follows: "He gave me a local anesthesia, so I saw almost everything that was going on. When he took out the baby, it made me feel strange to see him. It was strange and at the same time weird for me."

\section{Awakening and awareness of the baby}

There is here a logic in three stages: the awakening, the meeting of the newborn and the child mother relationship as it was originally lived.

\section{Awakening}

From the surgical point of view, this moment is important because it testifies to the fact that the patient did not succumb to the operation. The awakening is a dramatic moment for both the patient and the caregiver. Surgery and awakening are linked doubly to the experience of changes in the psycho-corporeal experience of the participants. This means that the true self and the false self are at the center of the subject's vital elements.

The various participants who were under total anesthesia woke up each in her own way. Ms. C presents the facts as follows: "A few moments later, I was injected and fell asleep. I woke up the next night and here I am." She testifies to her absence during the events of which she has no memory. Later, she shows her frustration at the strangeness of this baby that is presented to her and that she must accept "I woke up and two hours ago I was brought a baby. The nurse told me it's my baby, I took it, it's my baby." Ms. E talks about the pain and shock she experienced during anesthesia. Like the previous lady, she was not present at the event and said she did not know the sequence of events "when I was stung on the back before the operation, I felt as if the electricity hits. It hurts a lot and it's really traumatic. The rest, I do not know. I only saw the baby."

Ms. F woke up with a strange baby near her. This sense of foreignness suggests a danger. In this regard she said "I was stung and I fell asleep until yesterday or I found myself in this room with a baby next to me." In the case of the five women who have had general anesthesia, two are almost unresponsive. Mrs. A does not mention it at all. She reports just what happened before she entered the block. Ms. D did not make the transition from entering the block to the time of the interview. She just remembers the injection she received.

A collective approach of these five cases of awakening allows the following considerations: the women having undergone a general anesthesia do not know everything of the event of which they were supposed to be the actresses, and live a feeling of foreignness visa-vis this baby that they discover with them.

Ms. $B$ is the only one of the six participants who had a local anesthesia, she obviously does not talk about awakening since she did not fall asleep. However, she does not hide her anxiety before and during the operation that transpires through her exchanges with her doctor. "The doctor who operated on me was kind. He told me lots of stories and he also asked me to tell." She experienced the event until the exit of the baby who still appeared strange "He gave me a local anesthetic, so I saw almost everything that was happening. When he took out the baby, it made me feel strange to see him. It was strange and at the same time weird for me."

\section{Awareness of the newborn}

One of the fundamental moments of motherhood is the relationship between the mother and her baby. At this moment the mother is in contact with the real child who is no longer the imaginary child. Usually, the common experience of humanity is that of a lady who will experience the real child, but on the basis of previous sensations experienced during childbirth. They are thus guilty of linking the pain of childbirth to the quality of the child. This has no consequence in our sample for those who were under local anesthesia as for the other five.

\section{The meeting of the newborn}

Mrs. B saw the child come out of her belly, even though she did not feel it. She reports the following experience: "He gave me a local 
anesthesia, so I saw almost everything that was going on. When he took out the baby, it made me feel strange to see him. It was strange and at the same time weird for me. I just watched him and smiled." For the five other participants, some aspects of the meeting are common while others particularize the participants. Mrs. A speaks of her meeting with the newborn as a gift made to her or as a delivery "But here, they take you to the block and after they give you a child as if you had only adopted, as if you were incapable, as if you did not even have a word to say."

As for Mrs $\mathrm{C}$, her baby has remained a stranger whom she accepts in spite of herself. She does not acknowledge giving birth to this child, it was given to her. She reports, "I do not know what happened. I woke up and two hours later I was brought a baby. The nurse told me it's my baby, I took him, he is my baby." Ms. D does not particularly mention her meeting with the newborn. She evokes him as a being who was his companion in a bad situation and who survived with her "It was too complicated but thanks to God I am alive and the child too".

Mrs. E was also faced with a strange baby that she did not feel or see coming. "The rest, I do not know. I only saw the baby." Mrs. F also found a baby near her when she woke up "I was stung and fell asleep until yesterday or I ended up in this room with a baby next to me". The common aspects in the meeting with the newborn are therefore this discovery when they wake up from a baby that has not been felt. These participants were asleep by anesthesia and woke up with a baby. In all five cases, the baby is a strange stranger that women discover when they wake up. There are some aspects, however, such as the case of Ms. C who needed the nurse's confirmation to receive the baby and realize that he is her's.

From a psycho-emotional point of view, the first relations between the mother and the child are fundamental in the construction of narcissism. They reassure the lady in her feminine status. This narcissistic dimension defines its subsequent experience in the mother-child dyad.

\section{The postoperative experience}

The post-operative experience involves the subject's relationship to his corporality, to his socialization.

\section{The relation of the subject to his corporeity}

The approach of the bodily self makes it possible to pose the specificities of the subject who may come to ask questions about what he was, what he is and what is 'he became ? Below we will present the facts as they are in our sample.

For Ms. A, we have a devaluation of the selfimage "I was operated on and it's ugly". Subsequently she reveals a feeling of castration, because her pregnancy seems to have been stolen. "I entered the block with my pregnancy and after, I was not pregnant anymore." Mrs. B evokes her scar as an inhibitor of her ability to procreate in the future "As I am already a little old, I wanted to align my children once but with the scar I do not think it will be possible again. I'm scared for my scar but I hoped to conceive even after a year and a half. " Mrs. C also speaks of her scar which gives us unnecessary pain, because in comparison with the pain of the childbirth which would be rewarding, that of the cesarean section brings only sedentariness and disturbances "It is true that in the caesarean there is also suffering with this operation, the scar that hurts, there for example I have difficulty to get up, to walk; Even when I'm coughing, it hurts but I'm sure that both types of pain do not have the same effect." For Mrs. D, a surgical operation only intervenes to remove a bad object, she does not understand how she could be operated to give birth "Is it still weird you are operated to give birth? The others are operated because they have a disease like cancer, appendicitis. Do I work for the child? It's really terrible." Mrs. E also talks about her scar, which damages the self-image. It also evokes the pain that paralyzes her "It's still weird this story of cesarean section. You end up with a big scar on your stomach. It's ugly ! In addition it hurts. Look, I can not even go back. Even sitting 
down is a problem. Do not talk about it when I cough, it's like my belly is going to burst. " Ms. F refers to the violation of her bodily integrity. Her body has been mutilated "My body has become what we will tear at every moment'?

From these speeches of our participants, we can see that the self-image is put in pain, the pain is considered useless and especially what is particular, it is the mutilating aspect of the caesarean section.

\section{The subjects and their social experience}

Mrs. A declares her feeling of inferiority towards the women around her "To tell the truth, I am ashamed because I have the impression of not having been able like other women to give birth normally". She experiences a frustration with her delivery mode "You find yourself there with the other women while you did not push, it's really weird." She fears even more the reactions of her in-laws who have an accusing look "My husband is happy to have his child but I know that my inlaws will do the "kongossa." I know they will say that their son married a woman who gives birth only by cesarean section."

The eyes of others persecuting and alienating "Mrs. B "Here at home, people look at you differently when you have been operated on". She saw him much more with her mother-in-law who worries about her son's future. "Just when my mother-in-law came here, she looked at me strangely. I know she's wondering if I'll still be able to give birth."

Mrs. C's defense mechanisms are important, but she fears others' eyes." I'm still young, but it does not spare me comments. In any case I do not care I know that I did not do anything wrong. If anyone thinks I've done something, I do not care. I owe nothing to anyone." Mrs. D is prey to the eyes of others who accuse and persecute and try to defend themselves by defying her husband "People will say what they want. My mother-in-law, instead of asking how l'm doing, was quick to ask when I will be able to do the next child. "She will wait a long time. I feel that my husband is only going to take another woman to do the rest of his children. "

Mrs. E chooses to keep her secret operation in order not only to take shelter, but also to spare her parents. She seals a pact with her husband "Apart from my husband and I, nobody knows that I was operated on. I told my mother and my grandmother that I gave birth normally. My husband said the same thing to his family. I avoid bad comments. I prefer nobody to know the truth. I hope that here in the hospital nobody will tell them anything. I know that if my mother knows that I have been operated on, she will feel very bad, even worse, my grandmother. I prefer to keep this for my husband and me. We will manage. What is difficult is that we will not be able to hit the water and it can raise suspicions. It does not matter, will I find a way? Hey! I can not tell people. I really hope nobody will know, especially not the family". Mrs. F gets into conflict with Western culture and values the African woman "The truth is that we want to imitate the white things too much when it does not fit us. White women are lazy, so they are always in the hospital and they are also operated a lot."

\section{Conclusion}

In view of the above, cesarean delivery is questioned by the participants. This questioning draws its arguments from the fact that biological maternity has become a medical object, thus rationalizing the phenomenon. Reproduction has slipped considerably into the hands of experts, even though women's bodies have remained central. The leadership, culturally privileged in traditional obstetrics has become medical expertise. Thus, the extent of Caesarean section practice could have significant consequences not only at the individual level, but also socioculturally for women who go through this surgery. The evolution of this mode of delivery, taken more globally, is likely to have an impact on the emotional situation of women beyond the life of the mother and the child that is highlighted in her practice. This impact is worrying, because it 
creates a conflict between the psychological expectations of the mother and the survival of her fetus, conflict embellished by the experts who are often not listening to the psychic dynamics of parturients. The mother becomes just an ambulatory uterus from which to release the child. This negative consideration of her body implies that the cervix is no longer the place of passage but rather an object of mutilation. By creating a split between physical birth and psychic birth, the biomedical apparatus creates an absence and a feeling of lack in the caesarized parturients, causing them to feel guilty for not having fulfilled the moral and cultural obligation to give birth as the nature wants. In Caesarean section, there seems to be a lack of narcissistic investment in the reproductive system. Caesarized parturients feel guilty for not having given life according to the accepted model, both on the Divine level "You will give birth in pain" Genesis 3-6, social, cultural and psychic. They feel guilty for not being able to repeat the act that women have been doing in their environment since the beginning of time. For their own family they bring denigration, for the in-laws they are incapable, for the other parturients they are inferior, and for themselves they are guilty. Baumeister and al. (1994: 247) point out that guilt can serve as destructive projects that have a negative impact on socialization. The peculiarities of our participants' talk about cesarean section as a witness to the feeling of guilt can be summed up in the perception of themselves as insufficient mothers, the feeling of loneliness facing other mothers, the self-blame and the non-acceptance by the entourage. They range from denial to frustration, from anger to resignation. According to Mutryn (1984a, 1984b), the dedramatization of cesarean section would participate in its acceptance as a way to give birth as much as vaginal delivery, which would be desirable, even if we often consider surgery as an exceptional intervention, which only happens in extreme cases. Caesarean section can also be perceived as a means of countering pain, even if the refusal of pain is dependent on a particular socio-cultural context. Indeed for the African woman, the pain would be rewarding and help to prove the maternal capacity. Childbirth is a passage that is often eagerly awaited because it helps to discover the real child. All women are supposed to go through there, and succeed. Thus, the importance of saving the baby at all costs is partly motivated by the women themselves. In the name of this value, they even accept unconsciously that medicalization is becoming important. Some, however have a clear position. They question the practice of large-scale caesarean section. They want science to find other ways than caesarean section to save the mother and child. One of the solutions pending the new ways of science is the promotion of vaginal delivery after cesarean section (VBAC) so that the fear of ending up in cesarean one day, cesarean always leaves the cesarized parturients. This solution is significant not only for the maternal experience, but also for its symbolism.

\section{References:}

1. Amselek, C.B. (1998). Le mystère des mères. éditions Desclée de BROUWER.

2. André, J. (2009). Désirs d'enfant. Paris : PUF.

3. Antoine, C. (2007). La révolution intérieure, Psychologie de la grossesse et de la maternité. Edi-tions Larousse.

4. Baumeister et al. (1994). Guilt: an interpersonal approach. Psychol Bull. Mar;115(2):243-67

5. Bradley et al. (1983). Health Psychology: Process and Applications. Second edition, Anabel Broome and Sue Llewelyn: Chapman and Hall.

6. Breen, D. (1975). The birth of the first child. London: Tavistock publications.

7. Bydlowski, M. (2005). La dette de vie: itinéraire psychanalytique de la maternité. Paris: PUF.

8. Cohen, (1983). A global measure of perceived stress. Journal of Health and social behavior: Dec; 24(4):385-96.

9. Deutsch, H. (1945). The Psychology of Women: A Psychoanalytic Interpretation. Grune \& Stratton. Volume 2. Hush, A.; Bens, J. (2002). Checklist obstétrique. Stuttgart; G. Thieme Verlag.

10. Jones (1976)

11. Levine in (Brabant, 1987) . La césarienne a-t-elle une indication en cas de suspicion de macrosomie ? Journal de gynécologie obstétrique et de biologie de la reproduction 2000; 29: 22-29 : Masson, Paris, 2000. 
12. Mercer et al. (1983).

13. Mutryn, 1984a ; 1984b

14. Szejer, M. (2006). Pour une médicalisation raisonnée de la naissance. Protéger l'environnement de la naissance dans L'axe imaginaire et la réalité : écarts et décalages, $n^{\circ} 132,2006$.

15. Tsala Tsala JP. (2009). Familles africaines et thérapie. Clinique de la famille came-rounaise. Paris L'Harmattan.

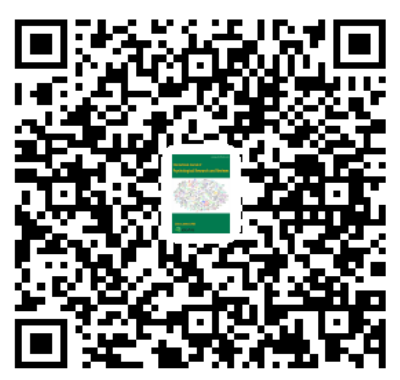

